Research Article

\title{
Study of Seismic Performance of Chinese-Style Single-Layer Suspended Ceiling System by Shaking Table Tests
}

\author{
Huanjun Jiang $\mathbb{D}^{1,2}$ Yong Wang $\mathbb{D}^{1,2}$ and Liusheng $\mathrm{He} \mathbb{C}^{1}$ \\ ${ }^{1}$ International Joint Research Laboratory of Earthquake Engineering, Tongji University, Shanghai 200092, China \\ ${ }^{2}$ State Key Laboratory of Disaster Reduction in Civil Engineering, Tongji University, Shanghai 200092, China \\ Correspondence should be addressed to Yong Wang; yongwang0305@163.com
}

Received 15 June 2021; Accepted 9 August 2021; Published 14 September 2021

Academic Editor: Baofeng Huang

Copyright (C) 2021 Huanjun Jiang et al. This is an open access article distributed under the Creative Commons Attribution License, which permits unrestricted use, distribution, and reproduction in any medium, provided the original work is properly cited.

During some recent earthquakes, the suspended ceiling system (SCS) in buildings suffered severe damage. The seismic performance of SCS attracted more attention from researchers. In this study, full-scale shaking table tests on two Chinese-style single-layer SCSs with different boundary conditions are conducted. The seismic damage and earthquake responses, including acceleration, displacement, and strain responses, are compared. The effect of the boundary condition on the seismic performance of the SCS is studied. It is found that the seismic performance of the SCS is significantly affected by the boundary condition. Compared with the SCS with the free condition at the boundary, the damage to the SCS installed with seismic clips at the boundary is much slighter. Compared with the SCS with the free condition, the median of acceleration amplification factor (AAF), the peak displacement (PD), and maximum strain of the SCS installed with seismic clips are reduced by up to $63 \%, 99 \%$, and $84 \%$, respectively. At the end of the tests, the SCS with the free condition at the boundary completely collapsed with $68 \%$ of the panels falling, while only $15 \%$ of panels fell in the SCS installed with seismic clips. The seismic clips could avoid the falling of the grids from the peripheral support and ensure the integrity of the SCS. With the help of seismic clips installed at the boundary, the responses of the ceiling, such as acceleration, displacement, and strain, decrease significantly, and thereof, the collapse resistance capacity is improved.

\section{Introduction}

The seismic damage to nonstructural components (NSCs) in buildings subjected to moderate or strong earthquakes in recent years was serious due to their high seismic fragility and insufficient seismic design, leading to great economic loss, interruption of building function, and even serious injuries and deaths [1-4]. For example, the statistical results show that NSCs represent $75 \%$ of the loss exposure of US buildings to earthquakes and account for over $78 \%$ of the total estimated annualized earthquake loss [5]. Many buildings remained unoccupied weeks after the 2010-2011 Canterbury earthquake sequences due to the damage to NSCs [6]. The falling of ceiling boards led to the loss of four lives in the 2011 Tohoku earthquake [7]. As one of the NSCs most popularly applied in buildings, the suspended ceiling system (SCS) with acoustic lay-in panels widely used in public buildings was seriously damaged during recent earthquakes. Extensive postearthquake investigations and experimental studies showed that the failure of the ceiling perimeter was one of the major reasons for the failure of the SCS [8-11]. In particular, the perimeter of Chinese-style single-layer SCS suffered severe damage in earthquakes due to the lack of reliable connections with the main structures, from which the damage usually started and spread to the interior of the ceiling. The peripheral grid ends in Chinesestyle single-layer SCS usually sit freely on the boundary in practice with only a small friction force; therefore, the ceiling perimeter is extremely prone to collide with the surrounding walls during earthquakes.

In recent decades, the seismic performance of the SCS with acoustic lay-in panels was investigated mainly by shaking table tests by many researchers $[8,12-20]$. Most of the SCSs tested in the past were typical American-style ceilings, whereas few studies examined the seismic performance of Chinese-style ceilings with different details from 
American-style ceilings. The main differences between Chinese- and American-style ceilings are as follows: (1) in Chinese-style ceilings, threaded rods are mainly adopted to hang the grid system, while in the American-style ceilings, hanging wires are adopted, and (2) the perimeter of Chinesestyle ceilings usually rests on surroundings without any constraints, while that of American-style ceilings is connected to the surroundings with pop rivets or seismic clips. The seismic clip connection constraining the peripheral grid to the boundary was proved to improve significantly the seismic performance of the SCS [21-23]. However, so far, no study has been conducted to investigate the effect of the seismic clip connection on the seismic performance of Chinese-style single-layer SCS. Although the seismic clip is recommended to constrain the peripheral grid to the boundary by Chinese standard J502-2 [24], it is applied rarely in China in practice, leading to the falling of the peripheral girds at the boundary and even triggering the continuous collapse of the ceiling during earthquakes. In this paper, the seismic performance of two Chinese-style singlelayer SCSs with different boundary conditions is compared by shaking table tests. The effect of seismic clips is studied.

\section{Chinese-Style Single-Layer Suspended Ceiling System}

2.1. Constitution of Single-Layer Suspended Ceiling System. The Chinese-style single-layer SCS considered herein comprises threaded rods, a grid system, and lay-in panels, as shown in Figure 1. Threaded rods are suspended from the bottom of the floor of the platform and adopted for hanging the grid system and lay-in panels. The grid system consists of main tees, cross tees, sub cross tees, and wall angles, forming a module for placing lay-in panels. The connection between the main tees is achieved by mechanically inserting the main tee end into the socket of the other main tee. The connection between the main tee and the cross tee is achieved by mechanically inserting two cross tee ends into the socket of the main tee. Similarly, the connection between the cross tee and the sub cross tee is achieved by mechanically inserting two sub cross tee ends into the socket of a cross tee. The threaded rod is directly connected to the main tee by a hanger, resulting in the single-layer connection between the threaded rod and ceiling grid. The threaded rods and ceiling grids are made of steel with the strength grade of Q235 having a yield strength of $235 \mathrm{MPa}$. The lay-in panels are made of mineral fiber with a mass density of $208 \mathrm{~kg} / \mathrm{m}^{3}$.

\subsection{Ceiling Perimeter Connection}

2.2.1. Free Condition. Two different types of boundary conditions, free condition and seismic clip connection, are studied in this test. For free condition, the peripheral grid ends just sit on the wall angle fixed on the perimeter beam using screws (Figure 2(a)). A clearance named as pounding gap exists between the peripheral grid end and wall angle. Due to the lack of precise control of the installation, the pounding gap in the SCS with free boundary condition at a different location was different. The mean value and standard deviation of the pounding gaps are $3.05 \mathrm{~mm}$ and $2.08 \mathrm{~mm}$, respectively. The mean value of the pounding gaps at different locations is regarded as the representative value for future analysis. Figure 2(b) shows the details of the free condition.

2.2.2. Seismic Clip Connection. There are two kinds of seismic clip connections (SCCs), that is, fixed connection and semifree connection. For fixed connection (FC), two screws in the grid-screw holes and one screw in the middle slot of the seismic clip are used for attaching the grid to the seismic clip. For semifree connection (SFC), only one screw is put in the middle slot of the seismic clip, allowing the grid to slide only along its axial direction, while the movement perpendicular to the axial direction of the grid is prevented. In addition, in the case of SFC, a nominal pounding gap of $19 \mathrm{~mm}$ between the grid end and wall angle is set, whereas no pounding gap exists in the case of FC. It should be noted that the actual mean value and standard deviation of the pounding gaps for SFC are $17.33 \mathrm{~mm}$ and $1.86 \mathrm{~mm}$, respectively. For the two types of SCCs mentioned above, the seismic clips are installed on the perimeter beam using four perimeter screws. Figure 3 shows the details of the seismic clip connection.

\section{Test Program}

3.1. Test Setup and Specimen. The steel platform with the plan dimensions of $12.84 \mathrm{~m} \times 11.64 \mathrm{~m}$ and a height of $5.40 \mathrm{~m}$ is adopted as a test carrier to hang the SCS. Figure 4 shows the steel platform. Three levels along with the height of the platform, table level, ceiling level, and floor level, are considered. In order to simulate the boundary condition of the specimen, the perimeter and middle beams are fixed on the platform to represent the surrounding walls. Moreover, the middle beam is adopted to separate the SCS into two comparative ceilings. The measured fundamental frequencies of the platform obtained by the transfer function method under white noise are $8.9 \mathrm{~Hz}$ in the $X$ direction and $8.4 \mathrm{~Hz}$ in the $Y$ direction, respectively.

The specimen consisting of two parts, B1 and B2, was designed and constructed. The two parts have the same layout but different boundary conditions. For B1, the boundary condition of the four sides is free. For B2, the boundary condition is fixed-semifree, which is realized by adopting fixed connections at two adjacent sides and semifree connections at other sides. The two parts are suspended from the bottom of the same floor of the platform to ensure the same input excitation. The overall view and photo of the specimen are shown in Figure 5. The grid system is suspended by means of threaded rods with a diameter of $8 \mathrm{~mm}$ and a length of $1000 \mathrm{~mm}$. The threaded rods are placed with an interval of $1200 \mathrm{~mm}$. The main tees are placed parallel to each other with an interval of $1200 \mathrm{~mm}$ along the $Y$ direction. The cross tees with the spacing of $600 \mathrm{~mm}$ are placed perpendicular to the main tees, and the sub cross tees with the spacing of $1200 \mathrm{~mm}$ are placed parallel to the main tees. The wall angles are fixed on the board of the perimeter beams and middle beams. 


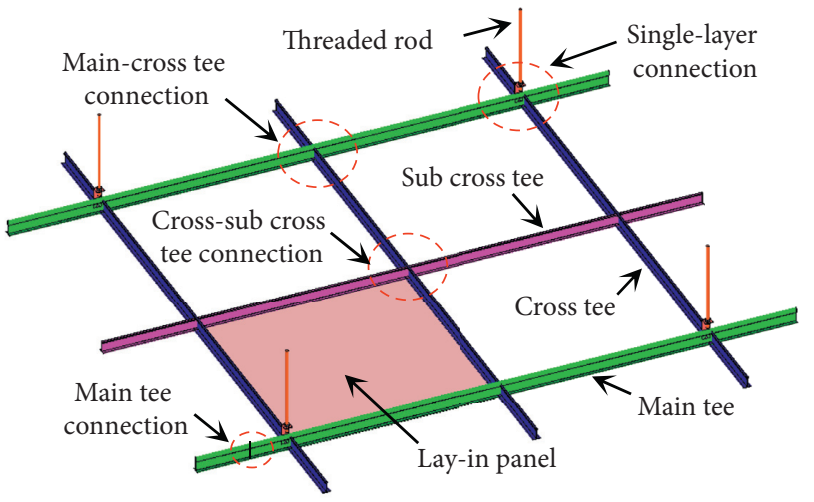

(a)
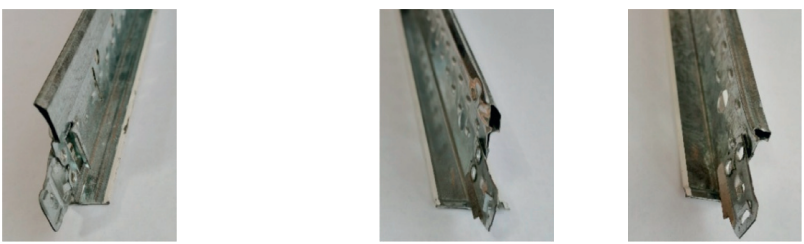

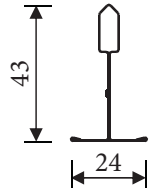

(b)
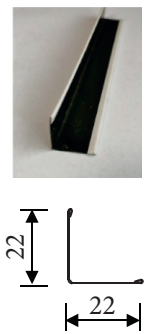

(e)

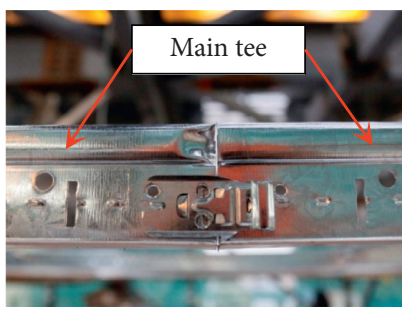

(i)

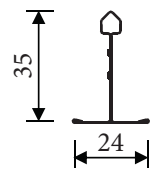

(c)

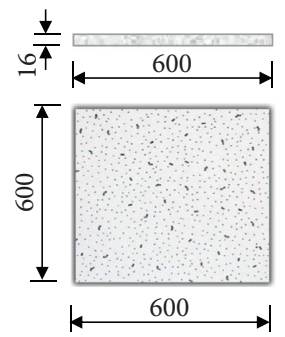

(f)

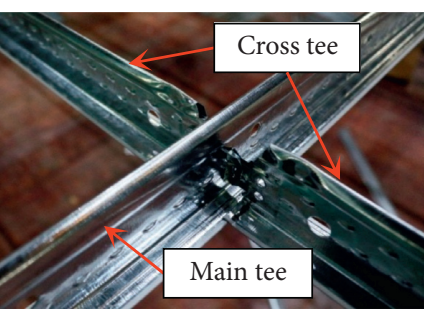

(j)

(g)
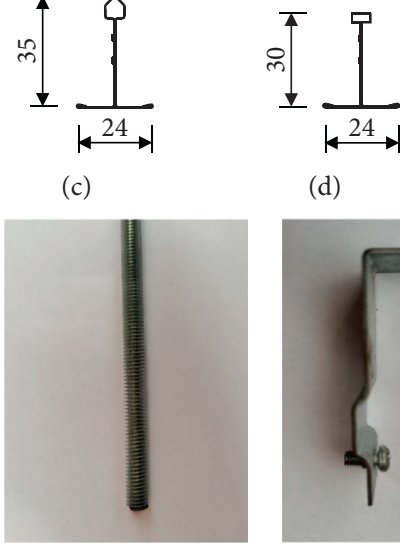

(d)

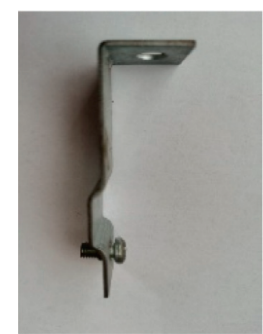

(h)

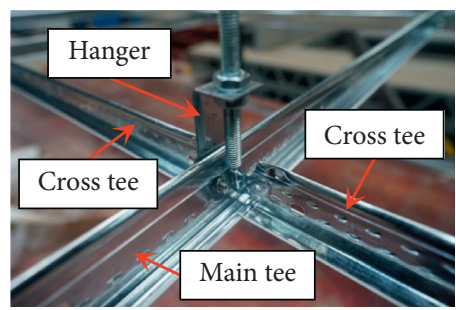

$(\mathrm{k})$

Figure 1: Constitution of Chinese-style single-layer suspended ceiling system. (a) Single-layer ceiling, (b) main tee, (c) cross tee, (d) sub cross tee, (e) wall angle, (f) lay-in panel, (g) threaded rod, (h) hanger, (i) main tee connection, (j) main-cross tee connection, and (k) singlelayer connection.

3.2. Instrumentation. For the platform, there are 3, 4, and 5 accelerometers installed on table level, ceiling level, and floor level, respectively, as shown in Figure 6. Accelerometers denoted as T1 to T3 are located on the left table center at table level. The acceleration of the table can be regarded as the input to the platform. Accelerometers denoted as P1 to $\mathrm{P} 4$ are placed at the mid-span of each perimeter beam at ceiling level. Accelerometers denoted as F1 to F5 are installed at floor level.

A total of 30 accelerometers are installed on the ceiling grids and lay-in panels to monitor the absolute acceleration of the specimen. The acceleration of the main tee and the cross tee corresponds to the $Y$ direction and $X$ direction acceleration, respectively. A total of 17 displacement 


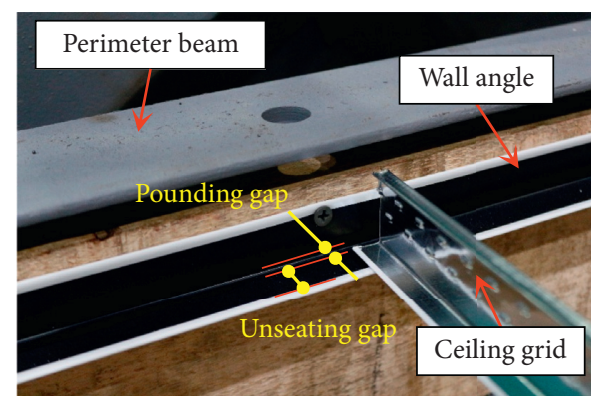

(a)

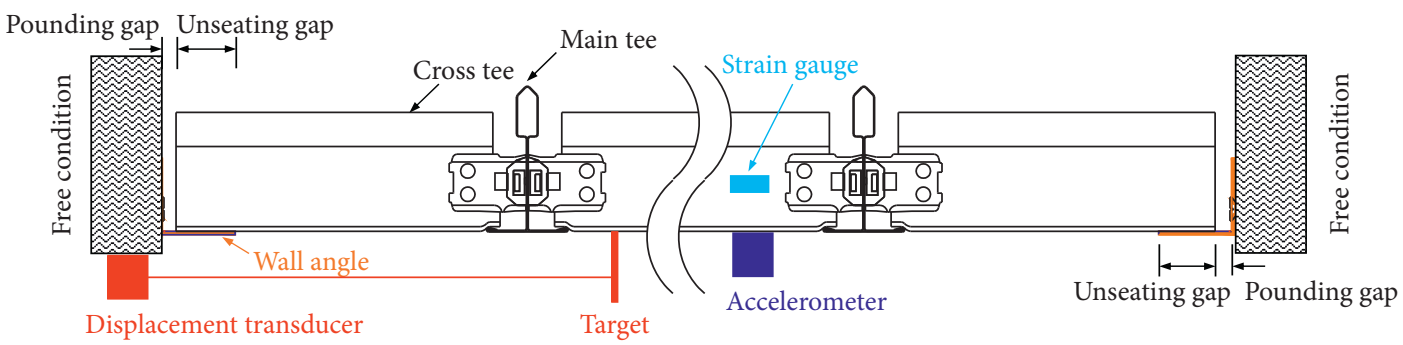

(b)

Figure 2: Free condition at boundary. (a) Connection and (b) details of connection.

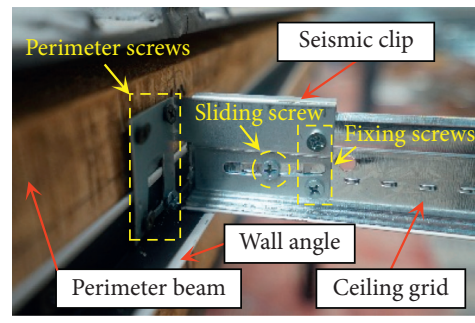

(a)

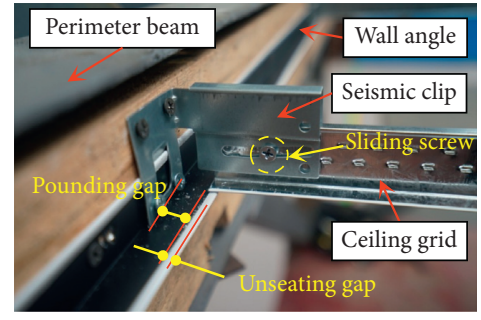

(b)

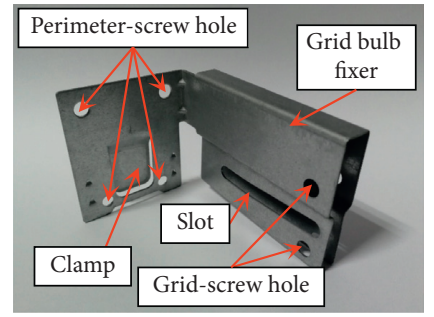

(c)

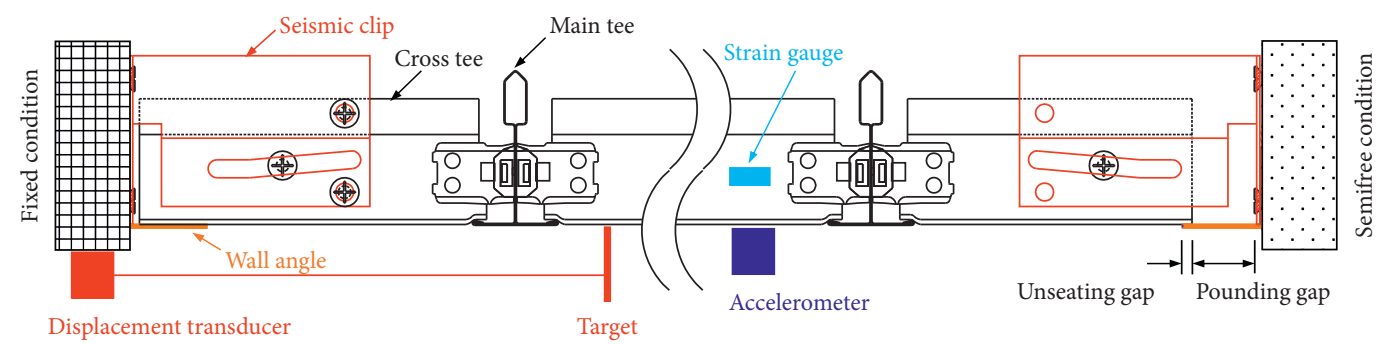

(d)

FIGURE 3: Seismic clip connection at boundary. (a) Fixed connection, (b) semifree connection, (c) seismic clip, and (d) details of connection.

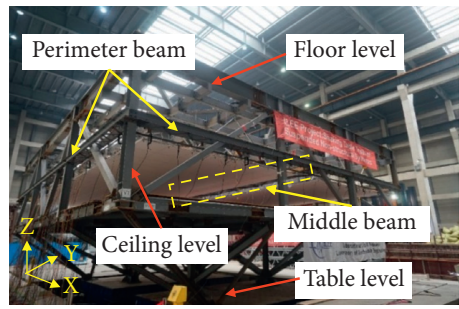

(a)

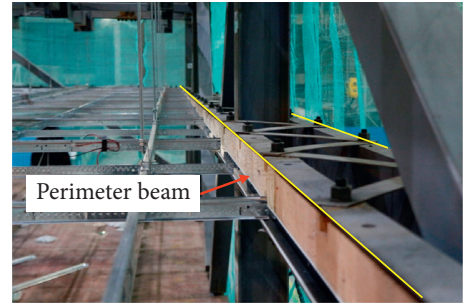

(b)

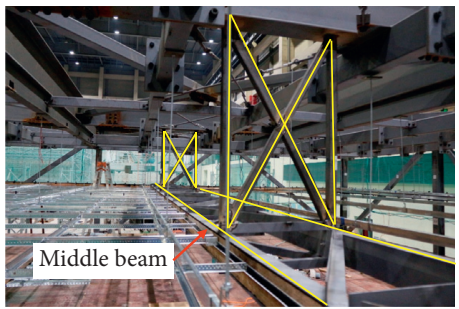

(c)

Figure 4: Test setup. (a) Overall view of steel platform, (b) perimeter beam, and (c) middle beam. 


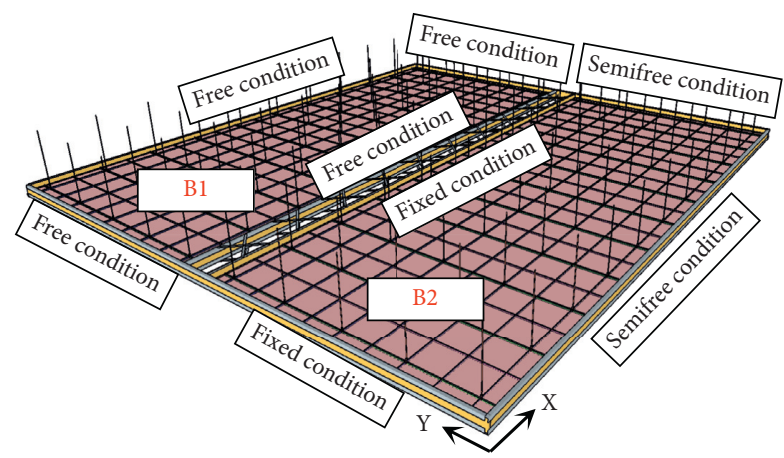

(a)

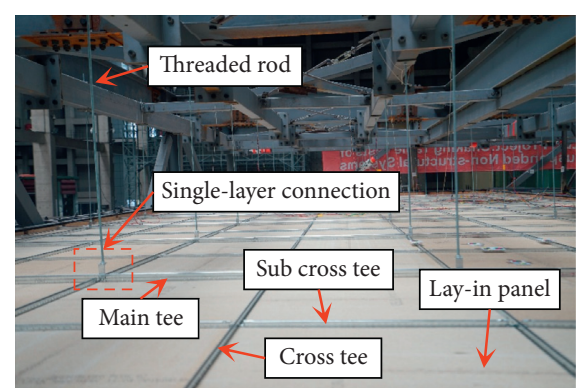

(b)

Figure 5: Test specimen. (a) Overall view of the specimen and (b) photo of the specimen.

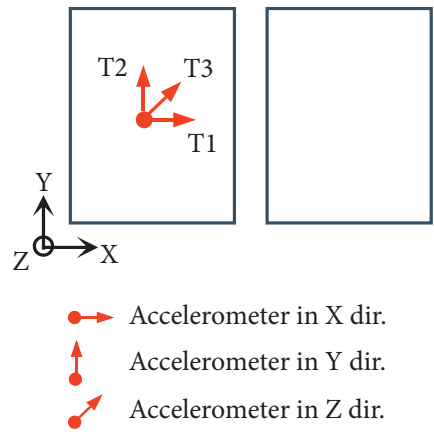

(a)

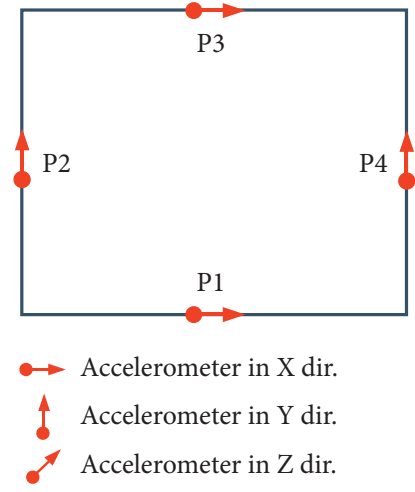

(b)

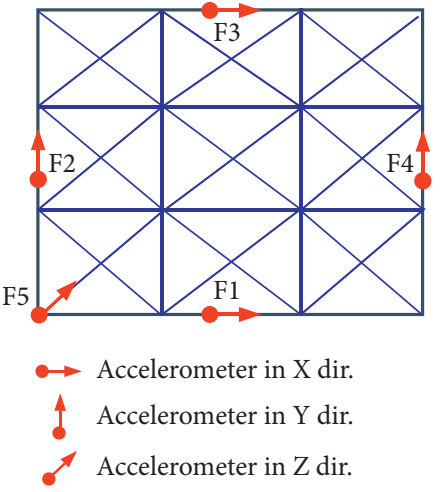

(c)

Figure 6: Accelerometers on the platform. (a) Table level, (b) ceiling level, and (c) floor level.

transducers are placed at the perimeter beams to monitor the displacement of the specimen relative to the platform. A total of 140 strain gauges are attached to the threaded rods, ceiling grids, and lay-in panels to monitor the local strain responses of the specimen. Except for lay-in panels with strain rosette installed, two strain gauges are attached to both sides of the same position of each ceiling component, and the average of the results obtained from two gauges is adopted in data analysis. Only the measurement points for subsequent analysis are marked. Figure 7 shows the location of instrumentation on the specimen. The hollow one-way red arrow and blue arrow represent the positive direction of displacement and acceleration, respectively.

3.3. Input Motions and Testing Protocol. Three types of motions are used for the input excitations, including sweep waves (named as sweep), acceleration responses at different floors of building structures obtained by time-history analysis, and artificial waves from the Building Center of Japan (named as BCJ-L2). The BCJ-L2 wave with a duration of $120 \mathrm{~s}$ is a Japanese artificial earthquake wave representing level 2 (design basis). The original PGA, PGV, and PGD of BCJ-L2 wave are $355.66 \mathrm{~cm} / \mathrm{s}^{2}, 53.37 \mathrm{~cm} / \mathrm{s}$, and $42.36 \mathrm{~cm}$, respectively. The sweep wave that is the sine wave with the variation of frequency from $5.0 \mathrm{~Hz}$ to $0.5 \mathrm{~Hz}$ or $0.8 \mathrm{~Hz}$ is generated to explore the failure mechanism of the specimen, as shown in Figure 8. Figure 9 presents the BCJ-L2 wave. The natural wave named SHW6 from Shanghai seismic design code [25] is input to a benchmark model of a 128-story supertall building structure and a 30 -story stick model. The acceleration response at the 5th floor and the top of the benchmark model and the acceleration response at the top of the stick model are derived and applied as the input motions (named as SHW6 (5/128), SHW6 (128/128), and SHW6 (30/ $30)$, respectively). Figure 10 shows the floor acceleration time history. All the motions input in the tests are summarized in Table 1. Figure 11 presents the acceleration response spectrum (ARS) with the damping ratio of $5 \%$ from runs 6 to 14 with the same peak acceleration of $0.1 \mathrm{~g}$. After each run, bidirectional white noise excitation is used to evaluate the dynamic properties of the specimen. The peak floor acceleration (PFA) of the platform is listed in Table 1. It should be noted that the PFA of the platform increases significantly from run 26 because of the looseness of some bolts of the platform subjected to the strong inputs.

Bidirectional white noise with the PGA of $0.05 \mathrm{~g}$ is input to identify the dynamic characteristics of the specimen. However, it is extremely difficult to identify the individual natural frequency of the specimen because the excitation intensity is observed to be too low to overcome the initial friction force existing in the specimen perimeter, which 


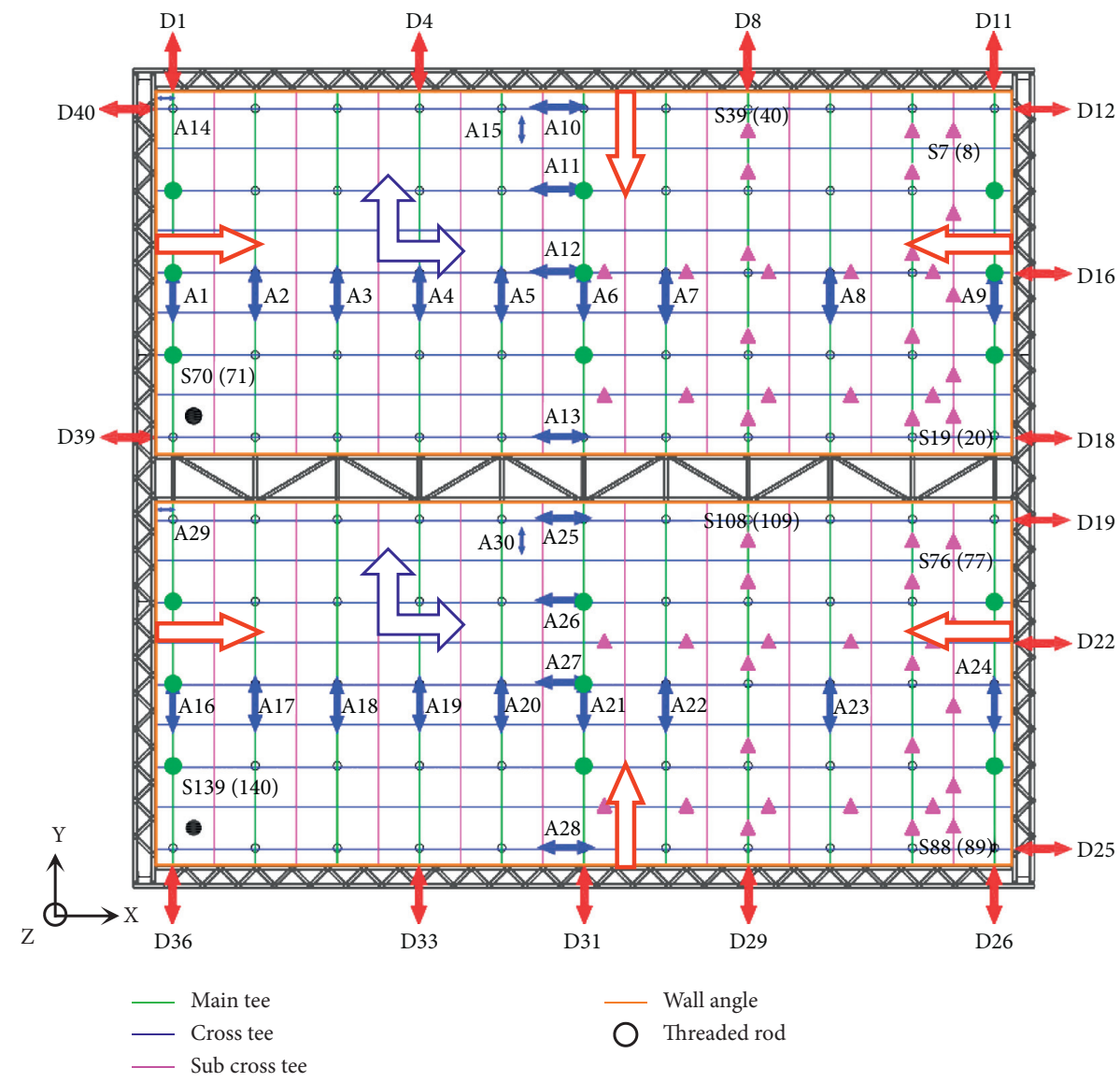

Figure 7: Instrumentation on the specimen. Notes: $\Leftrightarrow$ represents displacement transducer; $\leftrightarrow$ represents accelerometer; $\bullet$ represents strain gauge on the threaded rod; $\bullet$ represents strain gauge on lay-in panel; and $\Delta$ represents strain gauge on the main tee, cross tee, and sub cross tee.

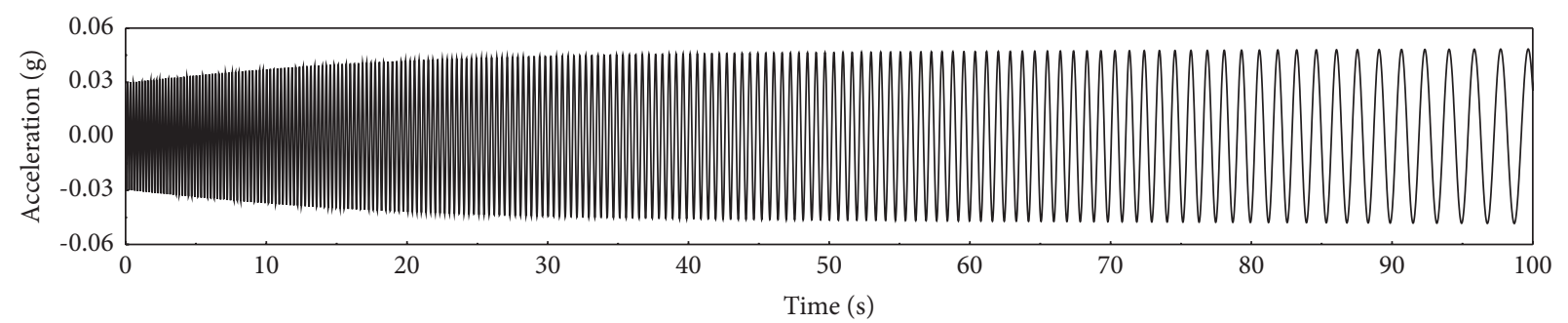

FIgURE 8: Sweep wave.

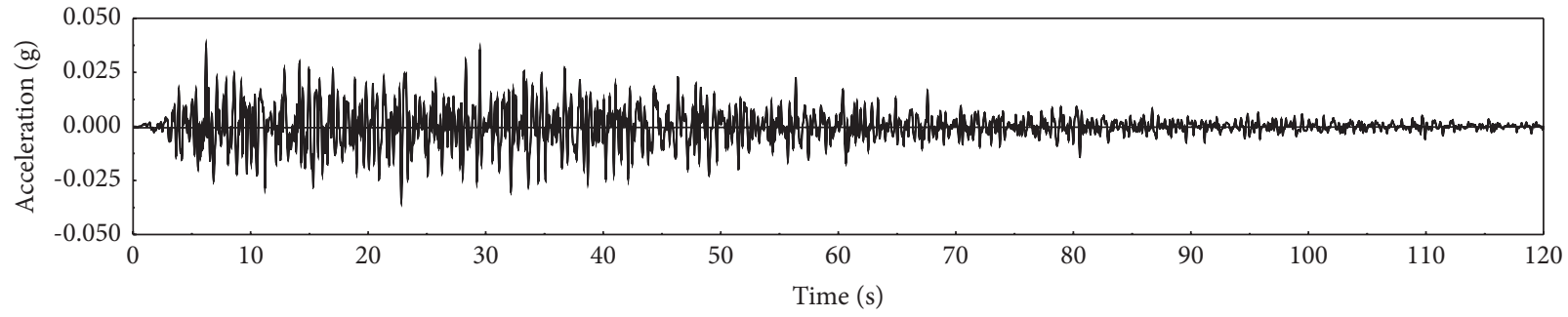

FIGURE 9: BCJ-L2 wave.

causes the specimen to move with the platform together. Hence, the natural frequency of the specimen derived by the transfer function method is very close to that of the platform.
Furthermore, the response of the specimen under the excitation of the sweep wave with the amplitude of $0.15 \mathrm{~g}$ is used to derive the natural frequency of the specimen. 


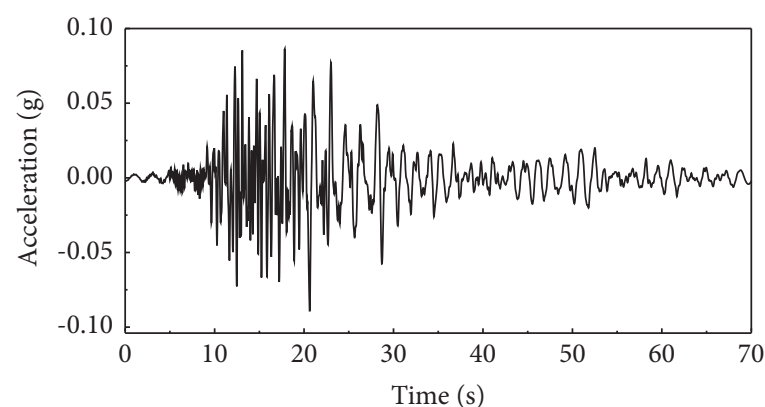

(a)

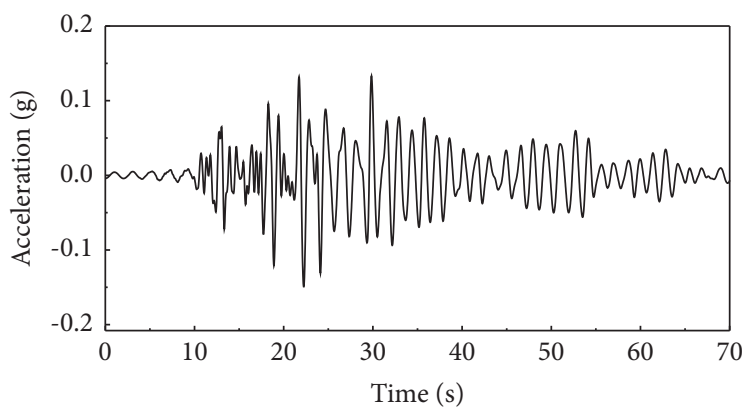

(c)

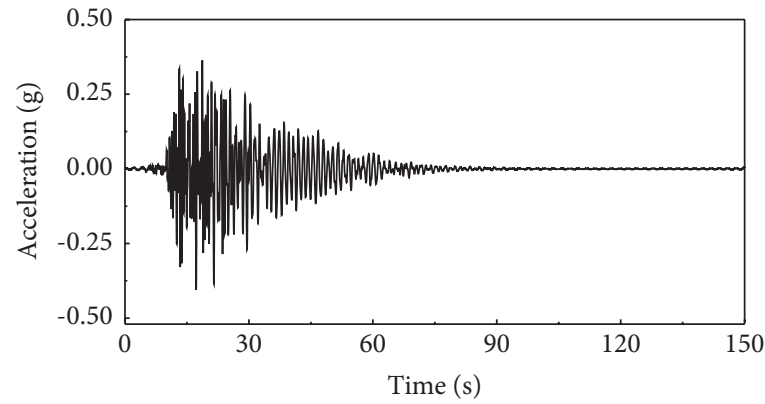

(e)

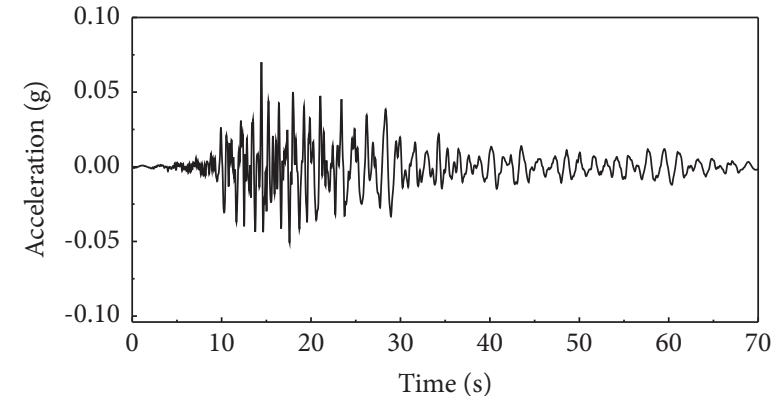

(b)

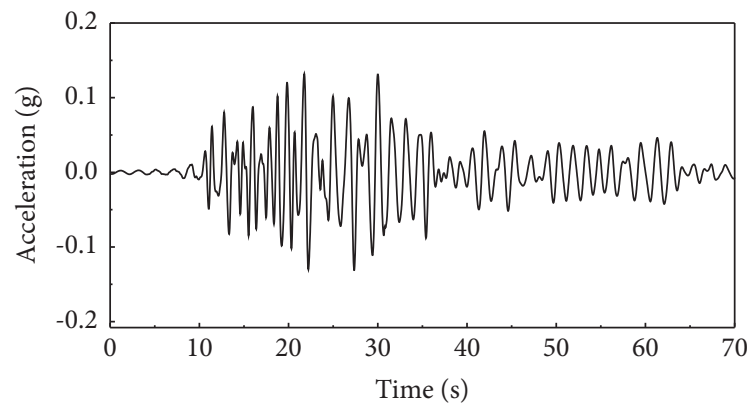

(d)

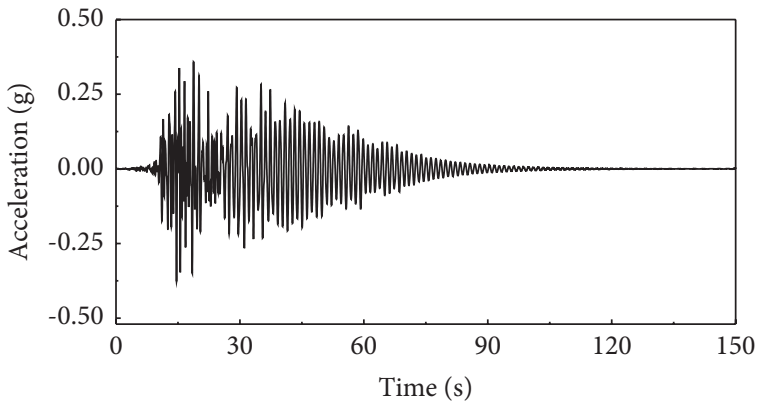

(f)

Figure 10: Floor acceleration time history. (a) SHW6 (5/128) wave in $X$ direction, (b) SHW6 (5/128) wave in $Y$ direction, (c) SHW6 (128/128) wave in $X$ direction, (d) SHW6 (128/128) wave in $Y$ direction, (e) SHW6 (30/30) wave in $X$ direction, and (f) SHW6 (30/30) wave in $Y$ direction.

TABle 1: Details of motions input to the specimen and peak floor acceleration of platform.

\begin{tabular}{|c|c|c|c|c|c|c|}
\hline \multirow{2}{*}{ Run no. ${ }^{1}$} & \multirow{2}{*}{ Name of input motion } & \multirow{2}{*}{ Loading direction } & \multicolumn{2}{|c|}{ Target acc. of table (g) } & \multicolumn{2}{|c|}{ PFA of platform (g) } \\
\hline & & & $X$ direction & $Y$ direction & $X$ direction & $Y$ direction \\
\hline 2 & Sweep & $X$ & 0.050 & 0 & 0.104 & - \\
\hline 4 & Sweep & $Y$ & 0 & 0.050 & - & 0.091 \\
\hline 6 & BCJ-L2 & $X$ & 0.037 & 0 & 0.063 & - \\
\hline 8 & BCJ-L2 & $Y$ & 0 & 0.037 & - & 0.055 \\
\hline $10^{2}$ & SHW6 (5/128) & $X-Y$ & 0.089 & 0.070 & 0.146 & 0.130 \\
\hline $12^{2}$ & SHW6 (128/128) & $X-Y$ & 0.149 & 0.132 & 0.168 & 0.177 \\
\hline $14^{2}$ & SHW6 (30/30) & $X-Y$ & 0.405 & 0.377 & 0.636 & 0.636 \\
\hline 16 & Sweep & $X$ & 0.150 & 0 & 0.284 & - \\
\hline 18 & Sweep & $Y$ & 0 & 0.150 & - & 0.405 \\
\hline 20 & Sweep & $X-Y$ & 0.150 & 0.150 & 0.368 & 0.453 \\
\hline 22 & Sweep & $X-Y$ & 0.150 & -0.150 & 0.490 & 0.612 \\
\hline 24 & Sweep & $X$ & 0.250 & 0 & 0.553 & - \\
\hline 26 & Sweep & $Y$ & 0 & 0.250 & - & 1.084 \\
\hline 28 & Sweep & $X$ & 0.350 & 0 & 0.970 & - \\
\hline 30 & Sweep & $Y$ & 0 & 0.350 & - & 3.350 \\
\hline 32 & Sweep & $X$ & 0.500 & 0 & 2.053 & - \\
\hline
\end{tabular}

Notes. ${ }^{1}$ Runs of odd numbers used for white noise excitation with small magnitude are not listed in the table. ${ }^{2}$ During runs 10 and 12 , the floor acceleration responses at the 5th and 128th floors of the 128-story building subjected to the ground motion SHW6 are input, and during run 14, the floor acceleration response at the 30 th floor of the 30 -story building is input. 


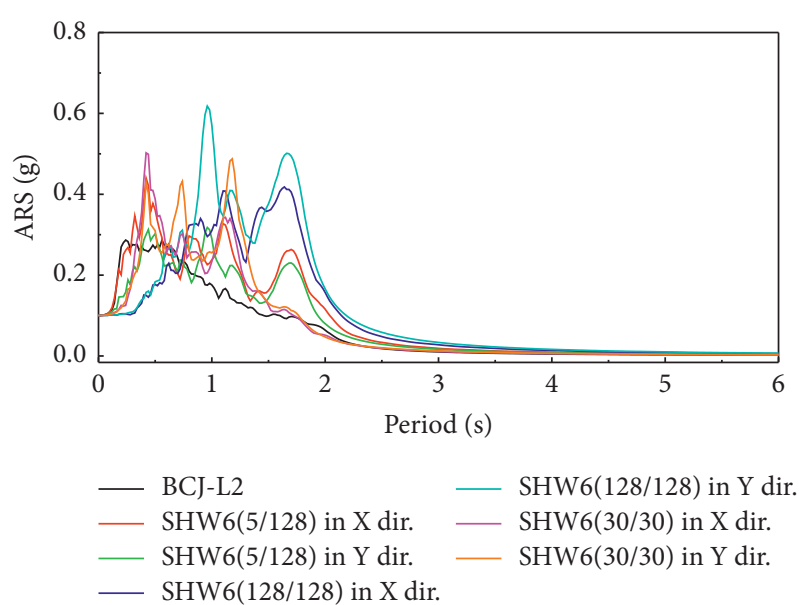

FIGURE 11: Acceleration response spectrum with the damping ratio of $5 \%$.

Although the friction force can be overcome during the input with higher intensity, the measured acceleration time history of the specimen is easily disturbed by the highfrequency spikes due to the powerful collision between the specimen and perimeter beams.

\section{Test Results and Discussions}

\subsection{Damage to SCS}

4.1.1. Damage Modes. The damage to B2 with seismic clips is significantly slighter than that to B1 with free boundary condition. The damage modes of the specimen during the shaking table tests are summarized in Table 2. The boundary condition has a significant impact on the damage modes of the SCS. B1 suffers more severe damage characterized by the unseating of grid and buckling of wall angle, while B2 does not suffer such kind of damage during the loading process, which proves that the seismic clips play the role in preventing the unseating of the peripheral grids from the wall angles and improving the seismic performance of the SCS. The typical damage to the specimen observed in the tests is shown in Figure 12.

4.1.2. Damage Evolution. The damage process of the specimen is demonstrated in Figure 13. No damage to the specimen was observed before the input motion of run 26 . Under run 26, the unseating of 3 grid ends from the wall angle, dislodgement of 2 panels near the unseating location, and shear deformation of 2 columns of main-cross tee connections near the $X$ direction ends were found in B1, while B2 remained undamaged. Under run 28, 6 columns of the main-cross tee connections buckled under axial compressive loads, and all the grid ends and surrounding panels at both ends in the $X$ direction suffered severe damage in B1. However, only a column of main-cross tee connections buckled due to axial compressive loads in B2. The maincross tee connections are vulnerable to axial buckling due to the reason that the compressive strength of the connection is much smaller than its tensile strength $[6,26]$. According to the static test on the connection, the average compressive and tensile strengths of the main-cross tee connection are $475 \mathrm{~N}$ and $1151 \mathrm{~N}$, respectively [27]. No significant damage continued to occur in B1 while the falling of 11 panels and dislodgement of 2 panels occurred in B2 under run 30. After the last run, B1 completely collapsed with the ratio of falling panels to total panels reaching $68 \%$. Part of main-cross tee connections failed, and 15\% of panels fell in B2. Compared with $\mathrm{B} 1$, the damage to $\mathrm{B} 2$ is much slighter, indicating that the Chinese-style single-layer SCS with seismic clips has better seismic performance than the one with free boundary condition. It should be noted that only the damage to lay-in panels is marked in the last run because the damage to other ceiling components is hard to count.

\subsection{Acceleration Response}

4.2.1. Acceleration Time History. The acceleration time history of the specimen under sweep waves with a PGA of $0.15 \mathrm{~g}$ is shown in Figure 14. The channels A12 and A27 are selected to compare the acceleration responses of B1 and B2 in the $X$ direction, respectively. The channels A6 and A21 are selected to compare the acceleration responses of B1 and B2 in the $Y$ direction, respectively. Under $0.15 \mathrm{~g}$ sweep waves, the acceleration response of B2 with seismic clips is significantly reduced compared with that of B1 with free boundary condition. Large acceleration amplification in B1 is caused by the severe pounding occurring at the ceiling perimeter. The movement of end grids in B2 is restrained by seismic clips so that the collision with the boundary is reduced.

4.2.2. Acceleration Amplification Factor. The acceleration amplification factor (AAF) is a key parameter affecting the seismic performance of the SCS. The AAF is defined as the ratio of the peak ceiling grid acceleration to the peak floor acceleration. The peak AAF prescribed in Chinese code GB 50011 (2010) [28] and American code ASCE 7-10 (2010) [29] takes the values of 2.0 and 2.5 for the SCS, respectively. The test data under earthquake waves (BCJ-L2, SHW6 (5/128), SHW6 (128/128), and SHW6 (30/30)) are used to calculate the AAF. Figure 15 shows the statistical parameters (maximum, minimum, and median) of the AAFs of the specimen. The median of the AAF is regarded as the representative value to compare with the code limit $[30,31]$. Most of the AAFs of B1 are larger than the code limit due to the violent collision at the ceiling perimeter while all AAFs of B2 are smaller than the code limit with the help of seismic clips. Compared with B1, the median AAFs of B2 under earthquake waves are reduced by $63 \%$ and $37 \%$ in the $X$ and $Y$ directions, respectively, indicating that the seismic clips could provide the constraint at the boundary effectively and significantly reduce the acceleration response of the SCS. The median AAF of B1 in the $X$ direction is larger than that in the $Y$ direction, which is attributed to smaller horizontal stiffness in the $X$ direction than that in the $Y$ direction. According to the test results, most of the AAFs of B1 are larger than the code limit, indicating that the code limit is not safe enough for the SCS with free 
TABle 2: Damage modes of the specimen during the shaking table tests.

\begin{tabular}{|c|c|c|c|}
\hline \multirow{2}{*}{ Damage no. } & \multirow{2}{*}{ Damage mode } & \multicolumn{2}{|c|}{ Specimen } \\
\hline & & B1 & $\mathrm{B} 2$ \\
\hline D1 & Unseating of grid & Yes & No \\
\hline D2 & Buckling of wall angle & Yes & No \\
\hline D3 & Axial buckling or shear deformation of main-cross tee connection & Yes & Yes \\
\hline D4 & Dislodgement of panel & Yes & Yes \\
\hline D5 & Separation of main-cross tee connection & Yes & Yes \\
\hline D6 & Falling of panel & Yes & Yes \\
\hline D7 & Separation of main tee connection & Yes & No \\
\hline D8 & Buckling of grid & Yes & No \\
\hline D9 & Deformation of hanger & Yes & Yes \\
\hline D10 & Falling of grid & Yes & Yes \\
\hline D11 & Complete collapse & Yes & No \\
\hline
\end{tabular}

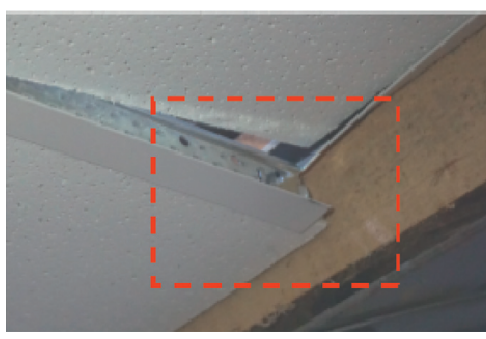

(a)

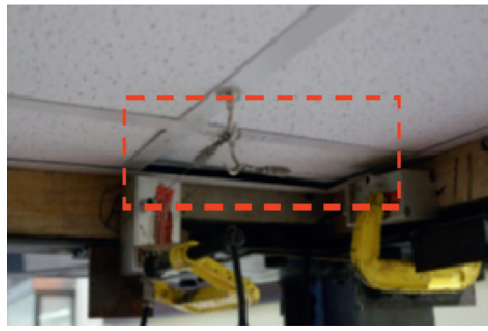

(d)

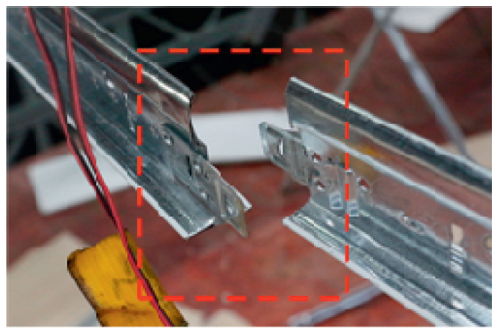

(g)

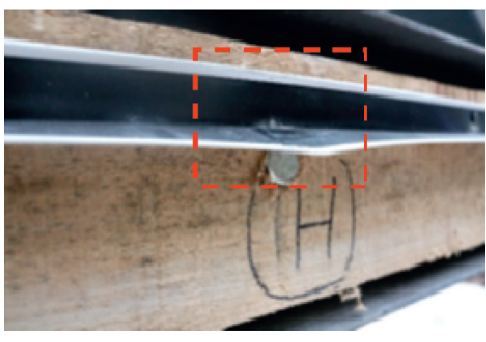

(b)

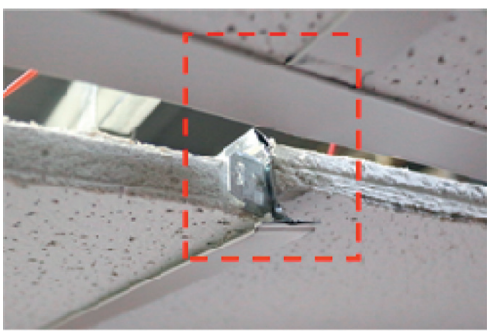

(e)

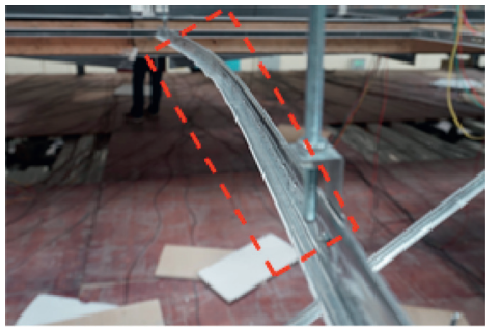

(h)

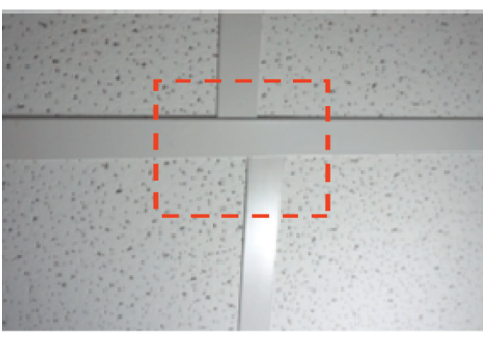

(c)

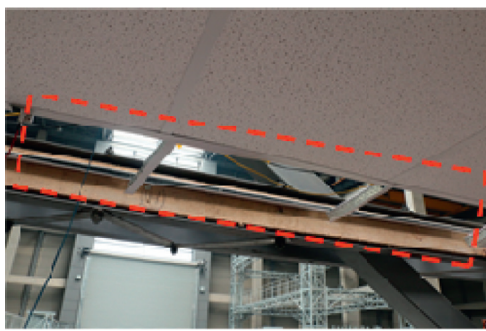

(f)

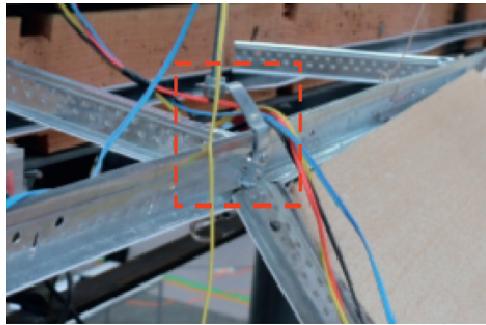

(i)

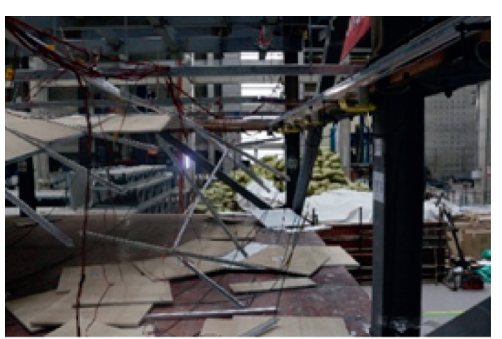

(j)

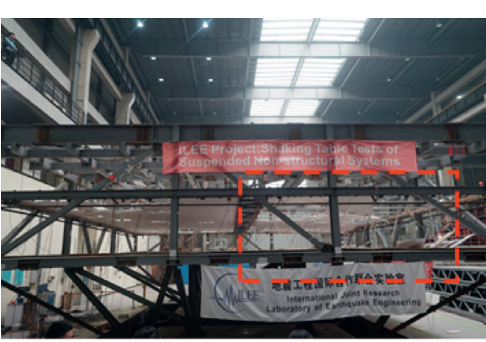

(k)

FIGURE 12: Typical damage to the specimen. (a) Unseating of grid, (b) buckling of wall angle, (c) axial buckling or shear deformation of main-cross tee connection, (d) dislodgement of panel, (e) separation of main-cross tee connection, (f) falling of panel, (g) separation of main tee connection, (h) buckling of grid, (i) large deformation of hanger, (j) falling of grid, and (k) complete collapse. Note: the damage modes of axial buckling and shear deformation of main-cross tee connection are basically similar. 


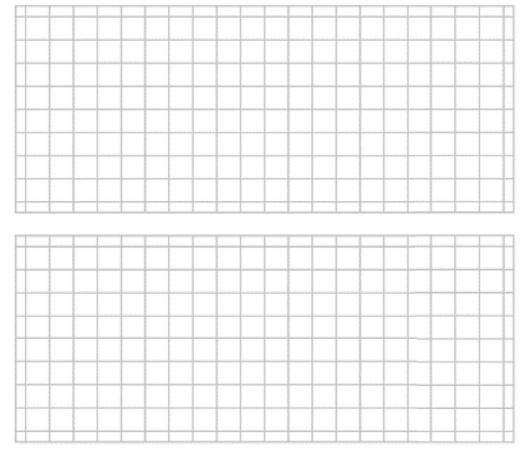

(a)
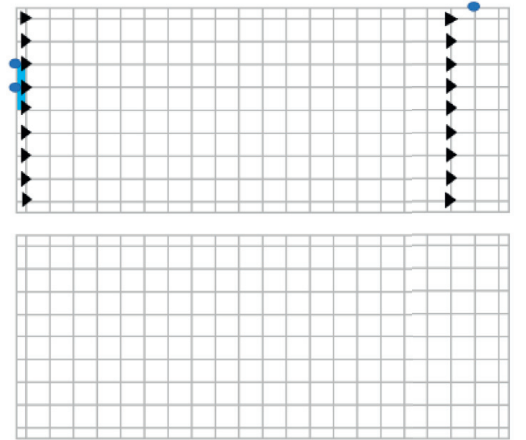

(b)
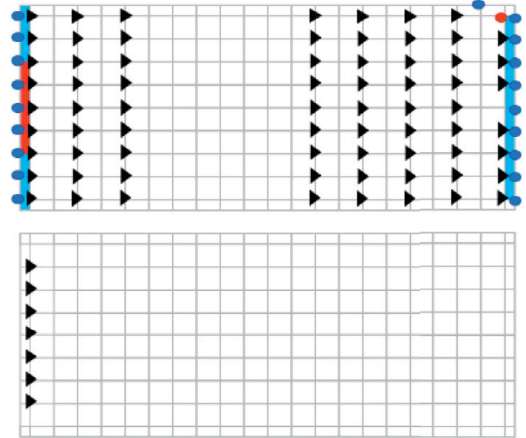

(c)
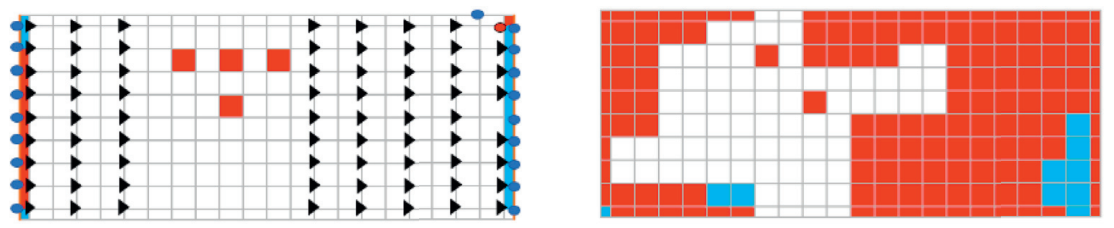

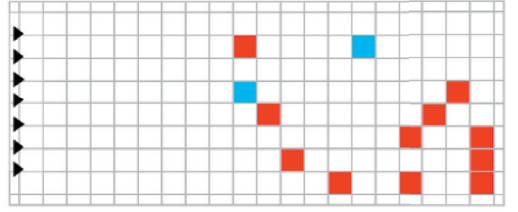

(d)

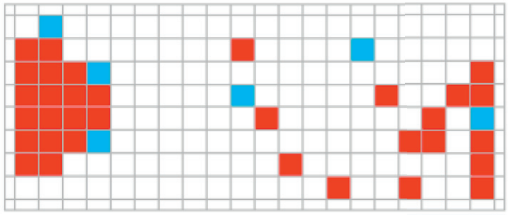

(e)

Figure 13: Damage process of the specimen. (a) Before run 26, (b) $0.25 \mathrm{~g}(Y)$ sweep (run 26), (c) $0.35 \mathrm{~g}(X)$ sweep (run 28), (d) $0.35 \mathrm{~g}(Y)$ sweep (run 30), and (e) $0.5 \mathrm{~g}(X)$ sweep (run 32). Notes: represents unseating of grid; — represents buckling of wall angle; represents axial buckling or shear deformation of main-cross tee connection; $\square$ represents dislodgement of panel; and represents falling of panel.

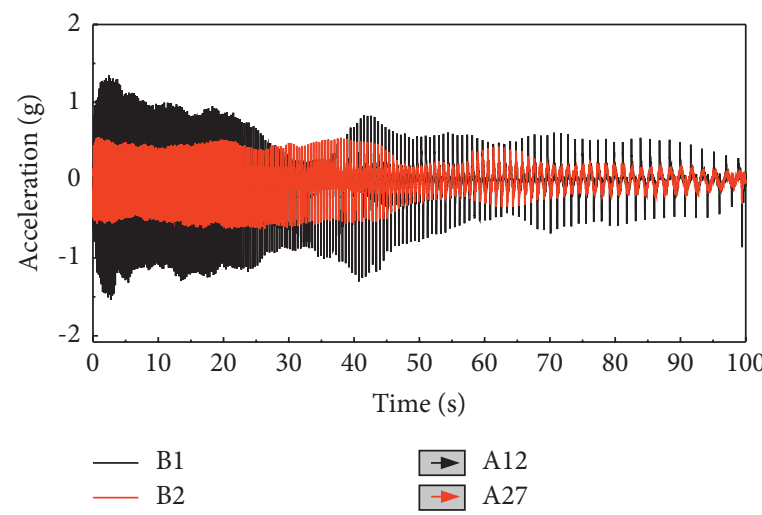

(a)

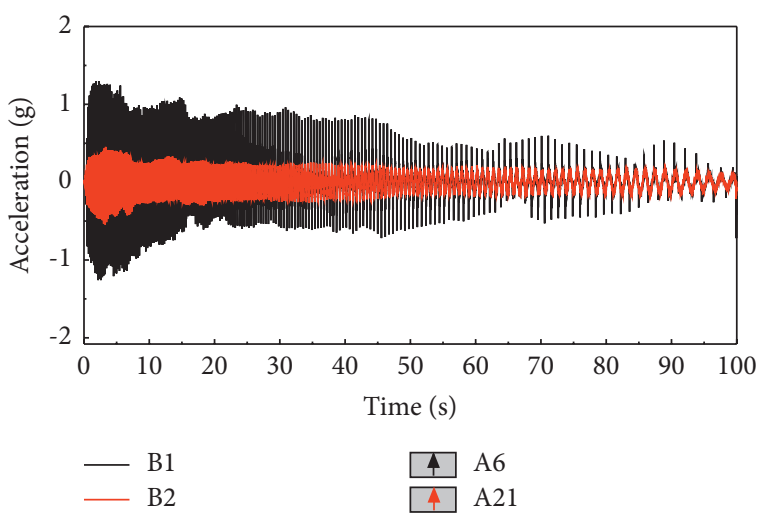

(b)

FIgURE 14: Acceleration time history: $0.15 \mathrm{~g}$ sweep. (a) Response in $X$ direction and (b) response in $Y$ direction.

boundary condition. On one hand, the code limit is an empirical value and lacks sufficient evidence. On the other hand, the code limit does not consider the effect of the boundary condition of the SCS. Therefore, the code limit needs to be further studied and clarified clearly.

4.3. PeakDisplacement. Figures 16 and 17 present the peak displacement (PD) versus PFA relationship under earthquake waves and sweep waves, respectively. Under earthquake waves, four kinds of input excitations, that is,
BCJ-L2, SHW6 (5/128), SHW6 (128/128), and SHW6 (30/ 30 ), corresponding to the inputs with PGA of $0.037 \mathrm{~g}$, $0.089 \mathrm{~g}, 0.149 \mathrm{~g}$, and $0.405 \mathrm{~g}$, respectively, are considered. Under sweep waves, three intensities corresponding to the inputs with PGA of $0.05 \mathrm{~g}, 0.15 \mathrm{~g}$, and $0.25 \mathrm{~g}$ are considered. Whether the inputs are earthquake or sweep waves, the PD increases as the PFA increases. Compared with $\mathrm{B} 1$, the PDs of $\mathrm{B} 2$ are reduced by $65 \%$ to $99 \%$ and $57 \%$ to $91 \%$ under earthquake and sweep waves, respectively. The PD of B2 is much lower than that of B1, which implies that seismic clips provide the restraint 


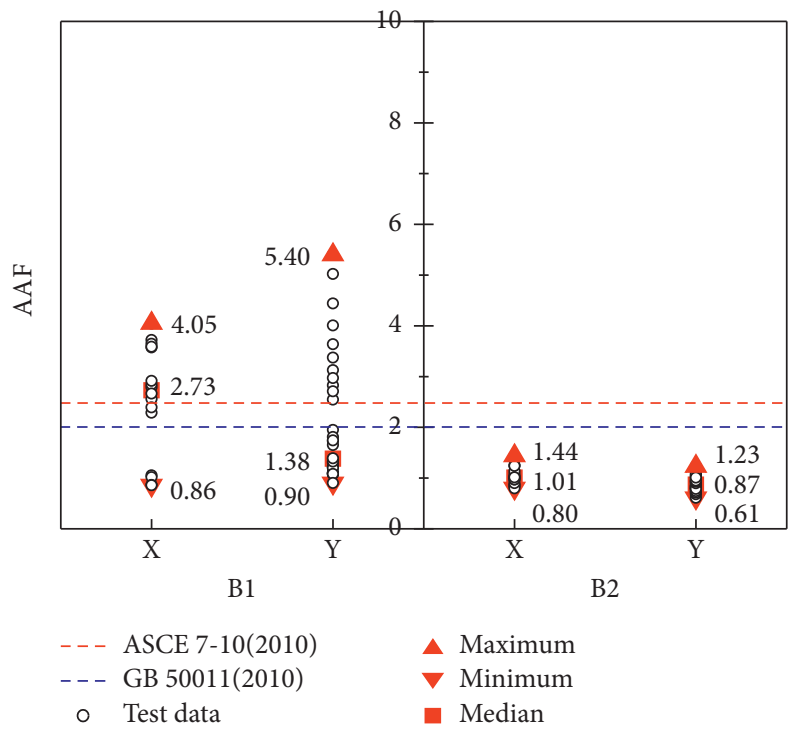

Figure 15: Acceleration amplification factor of the specimen.

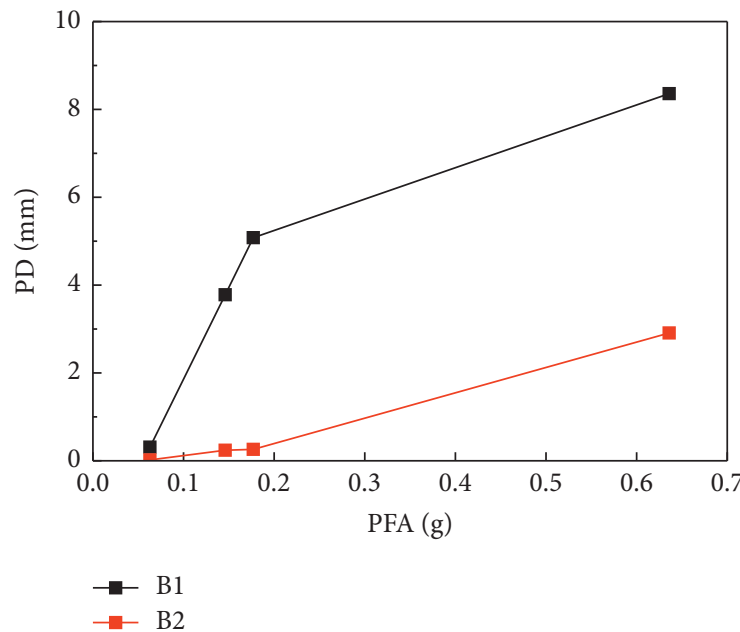

(a)

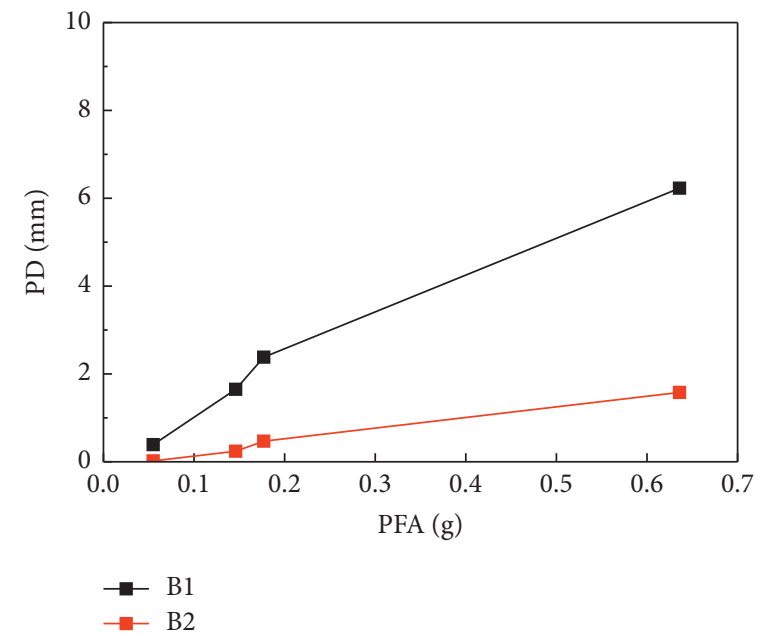

(b)

Figure 16: Peak displacement under earthquake waves. (a) Response in $X$ direction and (b) response in $Y$ direction.

effectively at the boundary and significantly reduce the displacement of the ceiling.

\subsection{Strain Response}

4.4.1. Maximum Strain of Ceiling Component. The maximum strain of $177 \mu \varepsilon$ measured on the ceiling components before the collapse of the ceiling is much lower than the yield strain of the ceiling components, which demonstrates that all ceiling components roughly remain elastic during the loading runs before the collapse of the ceiling. The reason is that the strength of the ceiling components is much larger than that of the grid connections. Hence, most damage to the specimen occurs at the connections rather than the components. The load-carrying capacity of the grid connection should be improved to avoid the premature failure of the connection.

4.4.2. Maximum Strain versus PFA Relationship. Figure 18 presents the maximum strain versus PFA relationship of the representative locations in the ceiling components under floor earthquake waves (SHW6 (5/128), SHW6 (128/128), and SHW6 (30/30)). The measuring points on the threaded rod of B1 and B2 correspond to S70(71) and S139(140), respectively. The measuring points on the main tee of B1 and B2 correspond to S39(40) and S108(109), respectively. The measuring points on the cross tee of $B 1$ and B2 correspond to $S 19(20)$ and S88(89), respectively. The measuring points on the sub cross tee of B1 and B2 correspond to S7(8) and S76(77), respectively. The measured 


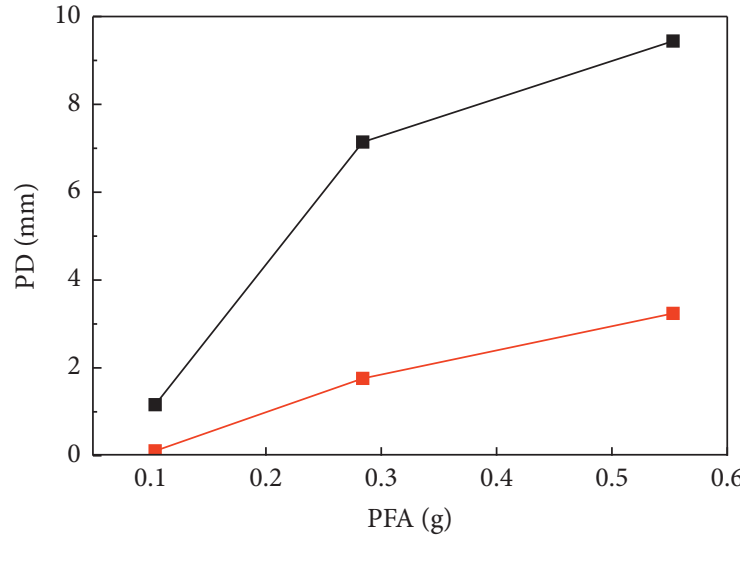

$\rightarrow B 1$

$\rightarrow \mathrm{B} 2$

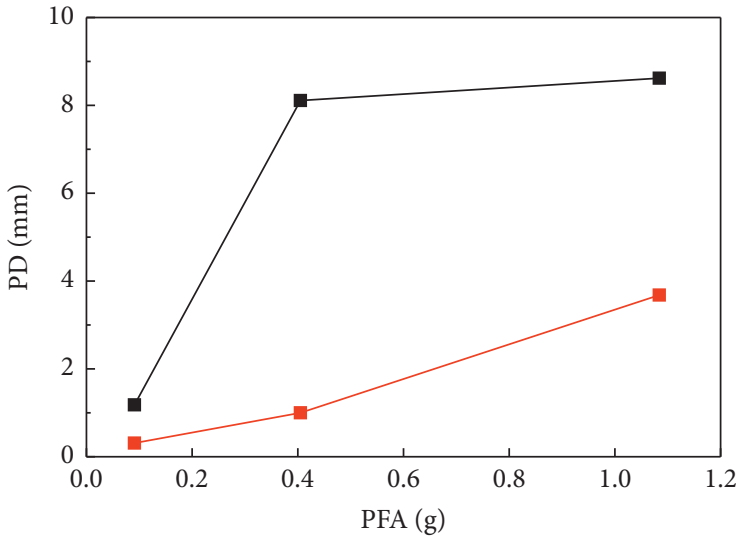

$\rightarrow-\mathrm{B} 1$

(a)

(b)

FIGURE 17: Peak displacement under sweep waves. (a) Response in $X$ direction and (b) response in $Y$ direction.
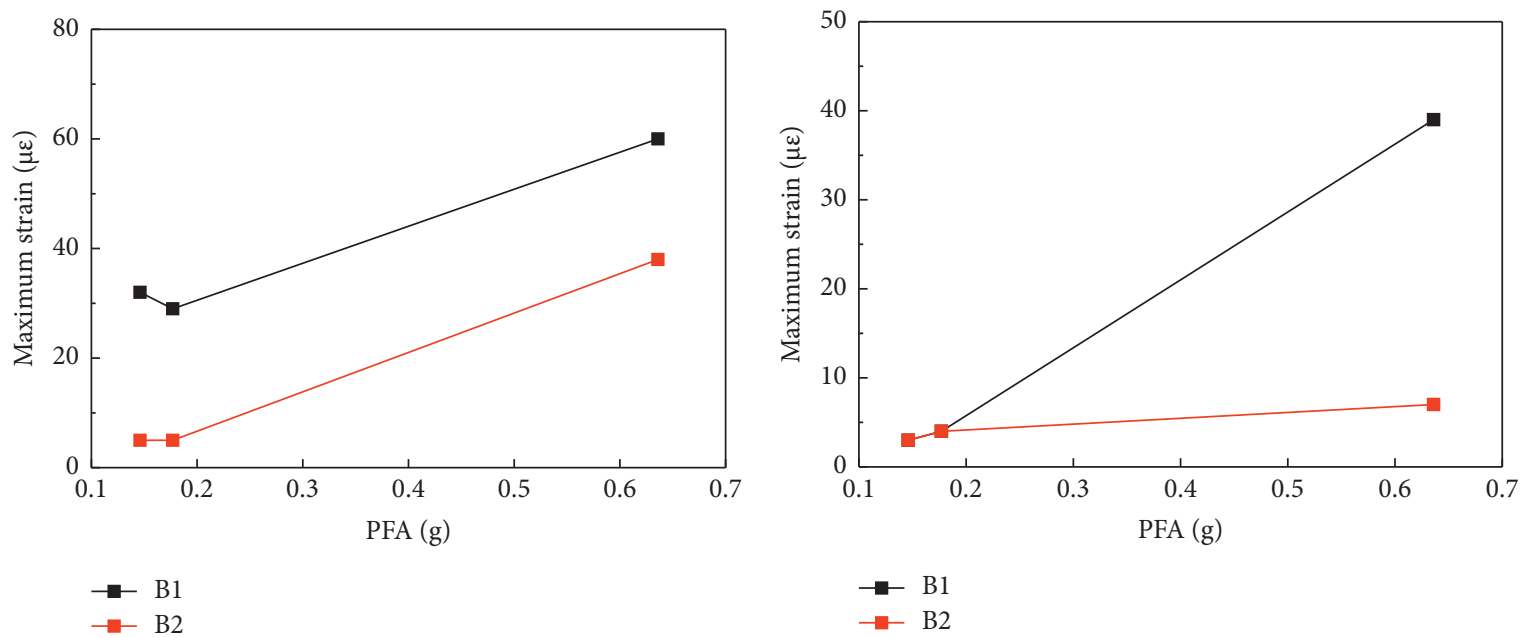

(a)

(b)

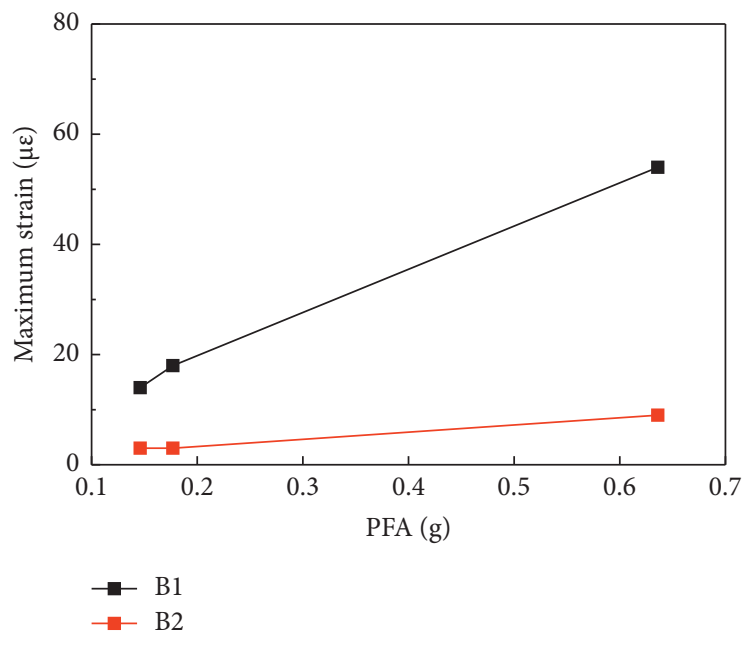

(c)

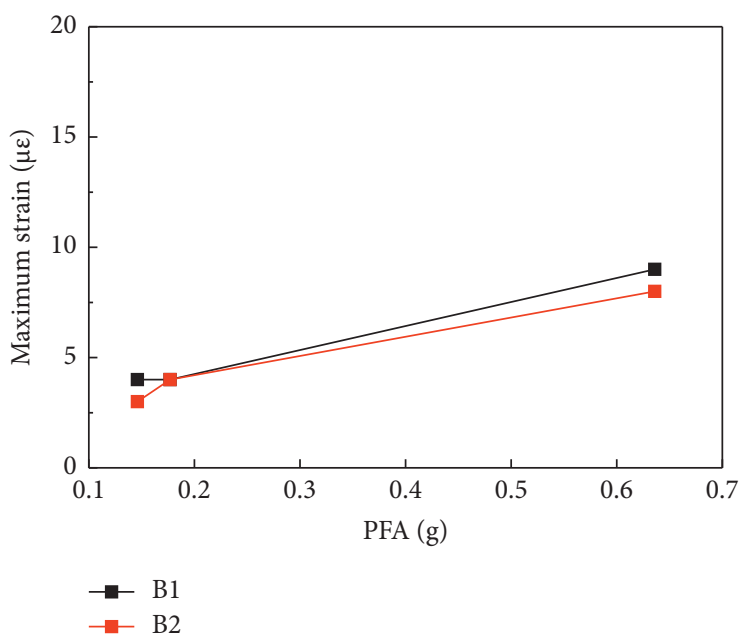

(d)

FIGURe 18: Maximum strain versus PFA relationship of ceiling components. (a) Threaded rod, (b) main tee, (c) cross tee, and (d) sub cross tee. 
strain on the threaded rod mainly reflects its bending deformation. The measured strain on other grids mainly reflects their axial deformation. The maximum strain of all the components generally increases as the PFA increases. The maximum strain of $\mathrm{B} 1$ is larger than that of $\mathrm{B} 2$. Compared with $\mathrm{B} 1$, the maximum strains on the threaded rod, main tee, cross tee, and sub cross tee of B2 under floor earthquake waves are reduced by up to $84 \%, 82 \%, 84 \%$, and $25 \%$, respectively. The larger strain of B1 is caused by the severe collision at the ceiling perimeter. The results indicate that seismic clips are effective to reduce the strain response of the ceiling components.

\section{Conclusions}

The full-scale shaking table tests are carried out on Chinesestyle single-layer SCS. The effects of the boundary condition on the damage and dynamic responses of the SCS are studied. The following conclusions can be obtained:

(1) In the SCS with free boundary condition, the peripheral connections and main-cross tee connections are most vulnerable to earthquakes and dominant to earthquake resistance capacity of the SCS.

(2) The damage to the ceiling with free boundary condition during seismic excitations starts from the peripheral connections and spreads to the inner parts of the SCS. The collision between the ceiling perimeter and the boundary adversely affects the seismic performance of the ceiling with free boundary condition.

(3) Compared with the SCS with free boundary condition, the seismic performance of the SCS installed with seismic clips at the boundary is much better. The boundary condition has a significant impact on the damage modes and seismic performance of the Chinese-style single-layer SCS.

(4) The seismic clips could effectively reduce the damage and dynamic responses of the ceiling so as to improve the seismic performance of the SCS. It is recommended that in practice, the peripheral grid ends of the ceiling should be restrained to the boundary by using seismic clips.

\section{Data Availability}

The test data used to support the findings of this study are included within the article.

\section{Conflicts of Interest}

The authors declare that there are no conflicts of interest regarding the publication of this study.

\section{Acknowledgments}

The authors acknowledge the financial support from the International Joint Research Laboratory of Earthquake Engineering of Tongji University (Grant no. 0200121005/058).

\section{References}

[1] E. Miranda, G. Mosqueda, R. Retamales, and G. Peckan, "Performance of nonstructural components during the 27 February 2010 Chile earthquake," Earthquake Spectra, vol. 28, no. S1, pp. 453-471, 2012.

[2] R. P. Dhakal, G. A. MacRae, and K. Hogg, "Performance of ceilings in the February 2011 Christchurch earthquake," Bulletin of the New Zealand Society for Earthquake Engineering, vol. 44, no. 4, pp. 377-387, 2011.

[3] K. Kasai, A. Mita, H. Kitamura, K. Matsuda, and A. Troy, "Performance of seismic protection technologies during the 2011 Tohoku-Oki earthquake," Earthquake Spectra, vol. 29, no. S1, pp. 265-293, 2013.

[4] D. Perrone, P. M. Calvi, R. Nascimbene, E. C. Fischer, and G. Magliulo, "Seismic performance of non-structural elements during the 2016 central Italy earthquake," Bulletin of Earthquake Engineering, vol. 17, no. 10, pp. 5655-5677, 2019.

[5] S. Taghavi and E. Miranda, Response Assessment of Nonstructural Building Elements. PEER Report 2003/05, Pacific Earthquake Engineering Research Center, California, CA, USA, 2003.

[6] R. P. Dhakal, G. A. Macrae, A. Pourali, and G. Paganotti, "Seismic fragility of suspended ceiling systems used in NZ based on component tests," Bulletin of the New Zealand Society for Earthquake Engineering, vol. 49, no. 1, pp. 45-63, 2016.

[7] M. Masato and M. Kazuya, "Building damage during the 2011 off the pacific coast of Tohoku earthquake," Soils and Foundations, vol. 52, no. 5, pp. 929-944, 2012.

[8] ANCO, Seismic Hazard Assessment of Nonstructural Ceiling Components. NSF Rep. No. CEE-8114155, ANCO, Culver City, CA, USA, 1983.

[9] S. Soroushian, M. Maragakis, and C. Jenkins, "Capacity evaluation of suspended ceiling-perimeter attachments," Journal of Structural Engineering, vol. 142, no. 2, Article ID 04015124, 2016.

[10] D. Wang, J. Dai, Z. Qu, and X. Ning, "Shake table tests of suspended ceilings to simulate the observed damage in the $M$ s7.0 Lushan earthquake, China," Earthquake Engineering and Engineering Vibration, vol. 15, no. 2, pp. 239-249, 2016.

[11] H. J. Jiang, Y. Wang, K. Kasai, S. Motoyui, and T. Chhat, "Shaking table tests on Chinese style suspended ceiling systems," in Proceedings of the 17th World Conference On Earthquake Engineering, Sendai, Japan, September 2020.

[12] S. S. Rihal and G. Granneman, Experimental Investigation of the Dynamic Behavior of Building Partitions and Suspended Ceilings During Earthquake. Rep. No. ARCE R84-1, California Polytechnic State University, Pomona, California, 1984.

[13] G. C. Yao, "Seismic performance of direct hung suspended ceiling systems," Journal of Architectural Engineering, vol. 6, no. 1, pp. 6-11, 2000.

[14] H. Badillo-Almaraz, A. S. Whittaker, and A. M. Reinhorn, "Seismic fragility of suspended ceiling systems," Earthquake Spectra, vol. 23, no. 1, pp. 21-40, 2007.

[15] A. S. J. Gilani, A. M. Reinhorn, B. Glasgow, O. Lavan, and H. K. Miyamoto, "Earthquake simulator testing and seismic evaluation of suspended ceilings," Journal of Architectural Engineering, vol. 16, no. 2, pp. 63-73, 2010.

[16] S. Soroushian, K. L. Ryan, M. Maragakis et al., "NEES/EDefense tests: seismic performance of ceiling/sprinkler piping nonstructural systems in base isolated and fixed base building," in Proceedings of the 15th World Conference on Earthquake Engineering, Lisbon, Portugal, 2012. 
[17] A. Pourali, R. P. Dhakal, G. MacRae, and A. S. Tasligedik, "Fully floating suspended ceiling system: experimental evaluation of structural feasibility and challenges," Earthquake Spectra, vol. 33, no. 4, pp. 1627-1654, 2017.

[18] Y. Lu, G. Mosqueda, Q. Han, and Y. Zhao, "Shaking table tests examining seismic response of suspended ceilings attached to large-span spatial structures," Journal of Structural Engineering, vol. 144, no. 9, Article ID 04018152, 2018.

[19] K. P. Ryu and A. M. Reinhorn, "Analytical study of large-area suspended ceilings," Journal of Earthquake Engineering, vol. 23, no. 4, pp. 592-624, 2019.

[20] S.-C. Jun, C.-H. Lee, C.-J. Bae, and K.-J. Lee, "Shake-table seismic performance evaluation of direct- and indirect-hung suspended ceiling systems," Journal of Earthquake Engineering, pp. 1-19, 2020.

[21] A. Pourali, R. Dhakal, G. A. Macrae, and A. S. Tasligedic, "Shake table tests of perimeter-fixed type suspended ceilings," in Proceedings of the 2015 NZSEE Conference, Rotorua, New Zealand, April 2015.

[22] S. Soroushian, E. Rahmanishamsi, K. P. Ryu, M. Maragakis, and A. M. Reinhorn, "Experimental fragility analysis of suspension ceiling systems," Earthquake Spectra, vol. 32, no. 2, pp. 881-908, 2016.

[23] S. Soroushian, E. Rahmanishamsi, C. Jenkins, and E. M. Maragakis, "Fragility analysis of suspended ceiling systems in a full-scale experiment," Journal of Structural Engineering, vol. 145, no. 4, Article ID 04019005, 2019.

[24] J502-2-2012, Indoor Decoration: Suspended Ceiling Inside, China Planning Press, Beijing, China, 2012.

[25] Standards Press of China, DGJ08-9-2013. Code for Seismic Design of Buildings, Standards Press of China, Shanghai, China, 2013.

[26] S. Soroushian, M. Maragakis, and C. Jenkins, "Axial capacity evaluation for typical suspended ceiling joints," Earthquake Spectra, vol. 32, no. 1, pp. 547-565, 2016.

[27] H. J. Jiang, Y. Wang, and C. Wu, "Experimental study on the axial behavior of grid joints and splices of suspended ceilings," Engineering Mechanics, 2021.

[28] GB 50010-2010, Code for Seismic Design of Buildings, Architecture and Building Press, Beijing, China, 2016.

[29] ASCE/SEI 7-10, Minimum Design Loads and Associated Criteria for Buildings and Other Structures, American Society of Civil Engineers, Reston, VA, 2010.

[30] L. Qi, M. Kurata, Y. Ikeda, K. Kunitomo, and M. Takaoka, "Seismic evaluation of two-elevation ceiling system by shake table tests," Earthquake Engineering \& Structural Dynamics, vol. 50, no. 4, pp. 1147-1166, 2020.

[31] Z. Luo, J. Xue, T. Zhou, L. Qi, and X. Zhao, "Shaking table tests and seismic design suggestions for innovative suspended ceiling systems with detachable metal panels," Engineering Structures, vol. 232, no. 10, Article ID 111830, 2021. 